\title{
Organizing Wendelstein 7-X Device Operation
}

\author{
P. van Eeten, H.S. Bosch, R. Brakel, S. Degenkolbe and the W7-X Team
}

The super conducting stellarator Wendelstein 7-X [1] started its first operational phase in October 2015 at the MaxPlanck-Institute for Plasma Physics in Greifswald with the goal to verify that a stellarator magnetic confinement concept is a viable option for a fusion power plant, i.e. showing confinement comparable to tokamaks and running in steady state operation. Between 2015 and 2018 the first three experimental campaigns (operational phases) OP1.1, OP1.2a and OP1.2b of the W7-X stellarator have been successfully completed. Roughly 13 Months of operational time have been accumulated and have already shown the impressive capability and reliability of W7-X in achieving the physical and technical goals as set by the project. The working group Device Operation (DO) has implemented an organizational structure and workflow to ensure safe and reliable operation of the W7-X device.

DO is responsible for planning and executing the commissioning and operation of the W7-X device. The operations plan is based on the physics planning which is a selection of individual physics proposals keeping in mind the technical limitations of W7-X. The operations plan is iterated between the lead physicists and device operation team (DOT). The "technischer Leiter vom Dienst" (TLvD or Engineer in Charge) plays a central role within the DOT in coordinating and supervising the technical operation of W7-X.

To ensure safe and reliable operation of W7-X several procedures have been implemented and improved. This involves commissioning templates, checklists, procedures for e.g. plasma heating energy release, operation malfunction cards, logbooks, coordination meetings, duty-on-call and shift-planning.

This paper will summarize the organizational aspects of W7-X technical operation as performed in the first three phases. It will also provide an outlook on the upcoming OP2 (actively cooled divertor) with the requirements for technical operation regarding commissioning and operation towards steady state plasma operation.

Keywords: Wendelstein 7-X, Commissioning, Operation, Organisation, Responsibilities

\section{Introduction}

In this paper the organisation, responsibilities and procedures of the technical operation of W7-X are discussed. The organization of the scientific operation is only addressed in those cases where direct interaction with technical operation is present. The task of the radiation protection officer is not detailed here but he is overseeing all activities and is the main interface to the authorities regarding operation of this nuclear device.

\section{Organisational Structure}

The DOT consists of the Head of Operation (HO) / Technical Leader (TL), Engineer in Charge (TLvD), the Chief Operator (CO) and Responsible Officers (RO) for each of the main technical systems on W7-X, see Fig. 1.

The DOT has the task to provide the overall technical performance of the W7-X systems as such that this can be used as a solid base for successful scientific operation. These functionalities with their operational limits and the operation experience gained in the past have to be translated into plasma operation parameters.

\section{Head of Operation (HO) / Technical Leader (TL)}

The HO carries overall responsibility for the technical operation of W7-X and manages the operations department. This role also covers the task as Technical
Leader (TL), Head of CCB and the Commissioning Group [1].

\section{Technischer Leiter vom Dienst (TLvD)}

The TLvD has the task to supervise all technical aspects of W7-X day to day operation. This includes both the interaction between the different systems as well as preventing W7-X from exceeding any of the defined operational limits. In addition, the TLvD has to manage operational deviations including the required documentation. A team of specialists has been trained to to become a TLvD as this task requires full time (24/7) availability during operational phases due to shifts and duty on call.

\section{CoDaC Operater (CO) and CoDaC}

The CO has the task to manage both the central operational management (cOPM) and central safety system (cSS) [3] in the control room through the respective human machine interface (HMI) during the experiments and is being supervised by the TLvD.

The CoDaC-Department has a special position within the DOT as it has to cover a wide range of tasks consisting of the cOPM and cSS management as well as the fast control system for plasma operation and data-acquisition including post-processing and long-term storage, see chapters 6 and 7 . 


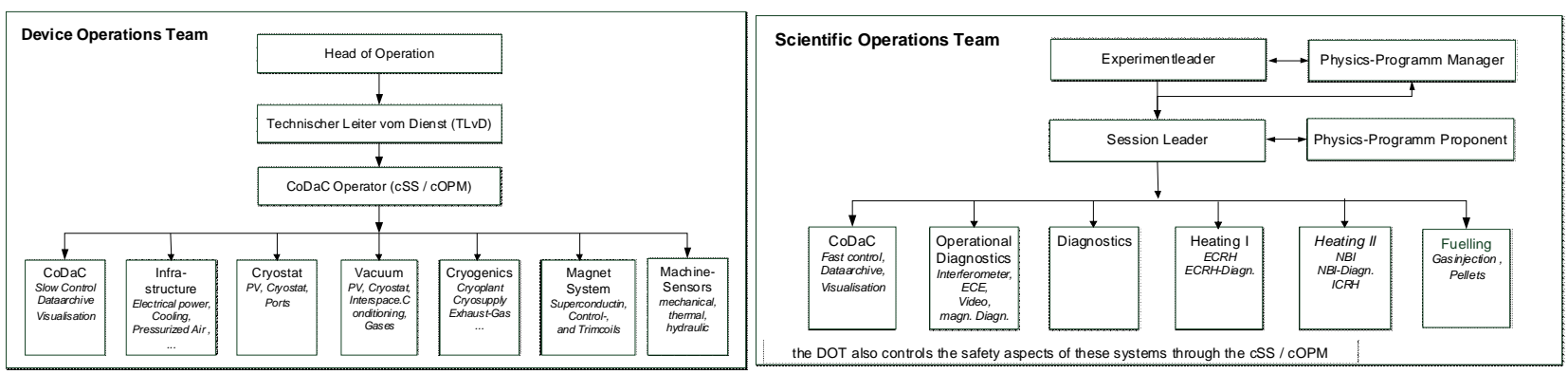

Fig. 1 Device and Scientific Operations Teams

Since $\mathrm{CoDaC}$ plays such a pivotal role in operation, it is of upmost importance to ensure adequate availability and quick response to issues arising. Similar to the Team of TLvD there is a trained team of CO to provide sufficient manpower to cover daily operation as well as duty-oncall.

\section{Responsible Officer Periphery}

For the different technical support systems of W7-X (cooling systems, pressurized air, gas supply, vacuum systems, cryo plant, Magnet system), the respective ROs are responsible for operation, maintenance and proper communication between system representatives in the main control room and the local control rooms (if present).

The scientific operations team is shown in Fig. 1 with the experiment leader (EL) being the main interface to the DOT. For individual plasma experiments, the respective physics-program-proponent is also involved in the coordination. The main roles in this organization are briefly described in this section.

\section{Experiment Leader}

The EL organizes the experimental campaign and makes sure that physics goals and the physical/technical condition of W7-X and its systems are compatible. The $\mathrm{EL}$ is also responsible for the session organization.

\section{Physics Program Manager}

The Physics Program Manager (PPM) is responsible for translating the general physics goals of a specific operational phase into a solid experimental program considering the technical boundary conditions of W7-X.

\section{Session Leader}

Physics programs are run in two experiment sessions per day. The session leaders (SL) are responsible for translating the proposed physics goals of a session as defined by the proponents into executable experimental programs considering the technical boundary conditions of W7-X. The SL manage the experiment sessions and make sure that physics goals and the physical/technical conditions of W7-X and its systems are compatible. The SL create, check and execute the segment programs for plasma operation [4].

\section{Physics Proponent and Session Organizers}

During each session one or more topical physics programs are being executed. These physics programs are based on physics proposals, each having a single proponent requesting for a certain number of plasma discharges with specific parameters. To each session an organiser is assigned who forms the interface between the EL and all other diagnosticians/physicists and will be active when his particular program is being executed. His main task is to coordinate the activities of all diagnosticians and the operations team to ensure a proper execution of the program taking deviations in diagnostics, heating systems or periphery into account.

\section{Responsible Officer Heating / Diagnostics}

These RO report to the SL. They have to make sure that their systems are in such a state as to enable proper execution of the planned physics programs. When deviations occur, they have to inform the EL, SL and TLvD immediately.

\section{Control Room}

The main control room of W7-X is located directly next to the Torushall at $2^{\text {nd }}$ floor level. Fig. 2 shows an overview of the main control room. Five circular working stations each containing roughly 10 network-clients and 20 seats each are available for diagnosticians, and positioned around the bell shaped central workstation.

The "Bell" is reserved for the DOT, EL and proponents. Its central location with the control room facilitates quick and direct communication with the physics representatives in the control room. The systems depicted in yellow have additional dedicated control rooms that are staffed with their experts during operation and commissioning. All of these systems must have a representative in the control room to enable direct communication with the TLvD and EL. Within the "Bell" the TLvD and EL have access to an audio system to make individual or pre-recorded announcements audible in all control rooms, offices (on network-clients) and the experiment area incl. Torushall. Fig. 2 indicates a large (width $\sim 8 \mathrm{~m} /$ height $\sim 1 \mathrm{~m}$ ) video display on the left side of the control room [5]. This display presents real time data on the most important experimental parameters and video footage of the plasma. 

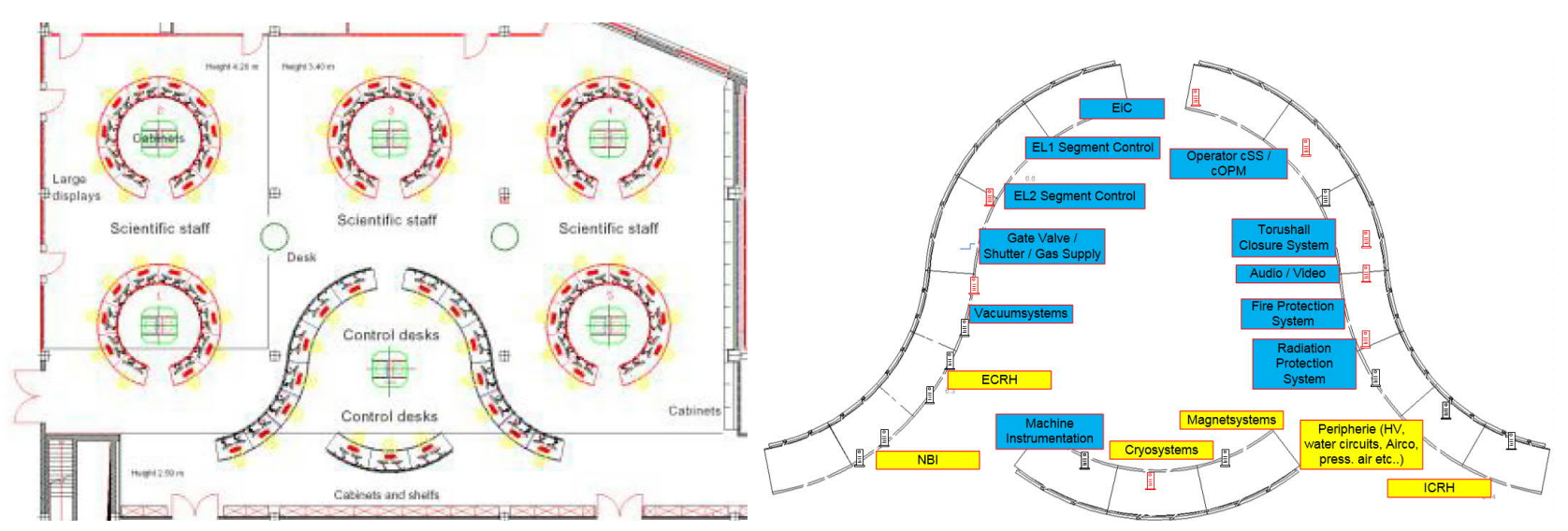

Fig. 2 Overview Main Control Room W7-X and Seating of technical Systems configured as a "bell"

It is visible from almost all seating positions within the control room. The footage as displayed on the screen is streamed through the network to provide the experiment status to the office buildings as well as to external institutes in Germany and abroad [5].

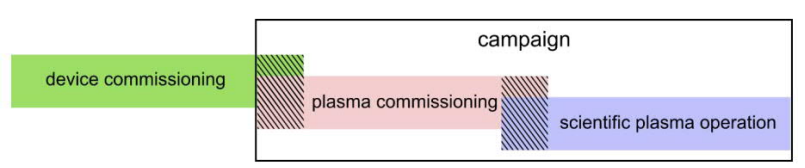

Fig. 3 Main phases for each W7-X campaign

\section{Operational Planning}

Each campaign has three main phases, see Fig. 3. The device commissioning covers all the preparations required to get all systems and diagnostics ready for the experimental campaign with main focus on the all technical systems, see [1][6][7] for further details on this phase. The detailed planning of a certain campaign (See example [8]) starts already months before commissioning by outlining the technical capabilities of W7-X for that specific phase, also based on the key programmatic research goals. This is an iterative process taking into account boundary conditions regarding assembly, schedule and financial restrictions. The research goals are broken down through proposals, prioritization and program planning to individual half-day sessions. Fig. 4 shows this process. This paper will not go into further detail regarding this process. It is clear though that any short-term changes/deviations to the technical configuration and capabilities of W7-X have to be taken into account in these session plans.

To ensure proper communication between physics and the DOT during operational phases several meetings have been established, see also

Fig. 5 and Table 1.

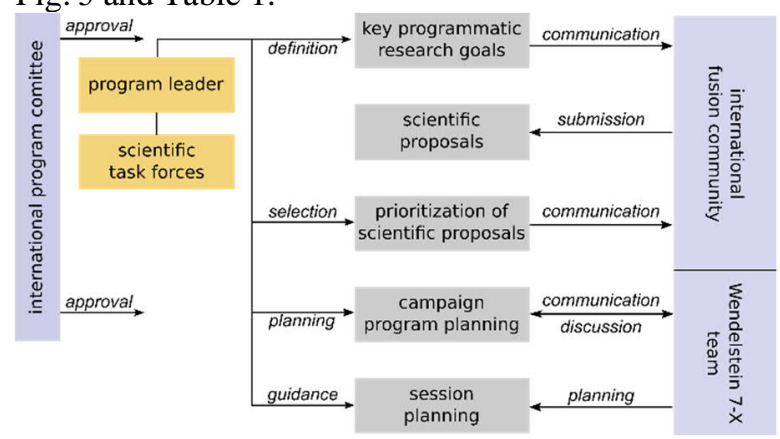

Fig. 4 Transition of key research goals into daily sessions

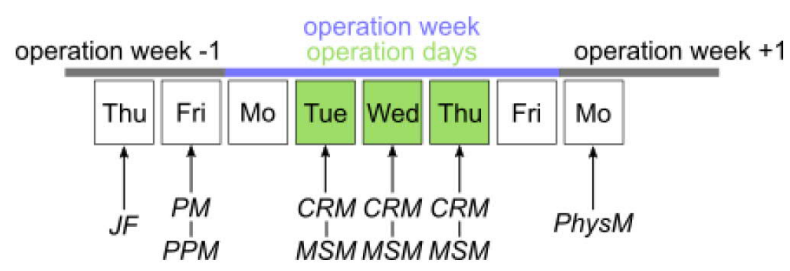

Fig. 5 Meetings associated with a week of operation.

\begin{tabular}{|c|c|}
\hline Meeting & Purpose \\
\hline $\begin{array}{l}\text { JF: jour fix program } \\
\text { detailing } \\
\text { Thu. } 8: 30\end{array}$ & $\begin{array}{l}\text { discussion of program detailing as } \\
\text { prepared by session organizers for } \\
\text { the upcoming week }\end{array}$ \\
\hline $\begin{array}{l}\text { PPM : program planning } \\
\text { meeting } \\
\text { Fri. 1:00pm } \\
\text { (remote participation) }\end{array}$ & $\begin{array}{l}\text { announcement of two weeks } \\
\text { session planning; update on } \\
\text { important developments; update } \\
\text { on machine status }\end{array}$ \\
\hline $\begin{array}{l}\text { CRM : control room } \\
\text { meeting } \\
\text { 8:00 on operation days. } \\
\text { For DOT during all week days }\end{array}$ & $\begin{array}{l}\text { clarification of the daily technical } \\
\text { machine component status; } \\
\text { Signing of work permits } \\
\text { Information about the key aspects }\end{array}$ \\
\hline $\begin{array}{l}\text { M SM : morning standup } \\
\text { meeting } \\
\text { 9:00 in control room on } \\
\text { operation days }\end{array}$ & $\begin{array}{l}\text { outline of the key physics and } \\
\text { operation aspects of the day }\end{array}$ \\
\hline $\begin{array}{l}\text { PM: physics meeting } \\
\text { Mo. 2:30pm } \\
\text { (remote participation) }\end{array}$ & $\begin{array}{l}\text { presentation of key physics } \\
\text { developments; short summary of } \\
\text { main session proposals; summary } \\
\text { of test results }\end{array}$ \\
\hline
\end{tabular}

Table 1 Regular meetings during operational phases

\section{Daily Operation}

A typical week of W7-X operation roughly looks like the schedule shown in Table 3. The experience during the last three OP has shown that minimum two non-operation days are necessary to provide sufficient access to the $\mathrm{TH}$ for modifications, adjustments and repairs to diagnostics and other systems. It also provides time to recap the previous week and adjust the detailed planning for the following week if required. For each day the DOT is split into two shifts. The DOT has to assure that manpower is available for all tasks and systems required for that particular shift. Plasma operation requires the complete DOT to be present. For special procedures like glow discharge cleaning a reduced number of personnel is 
required. To aid the DOT in setting up $\mathrm{W} 7-\mathrm{X}$ for plasma operation several checklists (CL) have been created that reduce the risk of operating errors and subsequent delays (Chapter 7). W7-X can be put into different states corresponding to different safety levels [9] as shown in

Fig. 6. Through these safety levels the cSS enables or disables operation of periphery, heating and diagnostics.

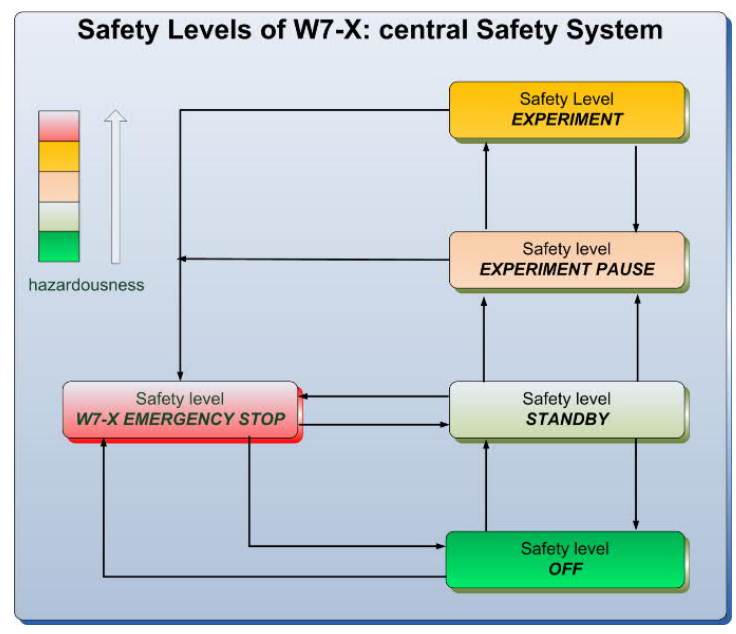

Fig. 6 Safety Levels in W7-X.

A change in operational state demands a change in safety level. During an operational campaign, several technical systems are continuously operating independent of plasma operation as shown in Fig. 7. This is mainly due to the cryogenic coil system remaining cold for the entire campaign [10]. That state requires $\mathrm{W} 7-\mathrm{X}$ to be in safety level Standby outside of plasma operation hours as it blocks plasma operation but enables running vital support systems.

\begin{tabular}{|l|l|}
\hline \multicolumn{1}{|c|}{ Typical timeline for an operational day of W7-X: } \\
\hline $\mathbf{0 7 : 3 0}$ & W7-X Status Standby; radiation protection area (RPA) accessible \\
\hline $\mathbf{0 7}: 45$ & Personnel evacuation of radiation protection area \\
\hline $\mathbf{0 9 : 0 0}$ & Finalize Checklist for Plasma Operation. \\
\hline & Change W7-X safety level: Experiment Pause \\
\hline $\mathbf{0 9 : 3 0}$ & Ramp Up main magnetic field \\
\hline $\mathbf{1 7}$ & Change W7-X safety level: Experiment \\
\hline $17: 45$ & Start Plasma operation \\
\hline End of plasma operation \\
\hline Change W7-X safety level: Standby \\
\hline TLvD > checklist for putting W7-X in Standby.
\end{tabular}

Table 2 Coarse overview of typical operational day
On a typical operational day the DOT has to transfer W7$\mathrm{X}$ into plasma operation state, safety level Experiment. A typical timeline for an operational day of $\mathrm{W} 7-\mathrm{X}$ is shown in Table 2.

\section{Monitoring}

The main responsibility of the DOT is to ensure that W7$\mathrm{X}$ is operated within its operational limits. The TLvD has the leading role in this task. The DOT has several tools to monitor the state of W7-X.

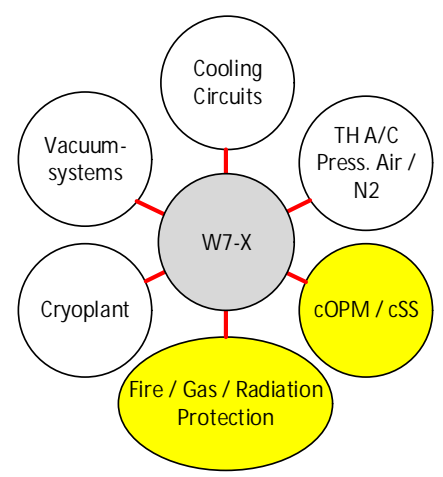

Fig. 7 Continuously active systems during an experimental campaign.

\section{cOPM/cSS}

The most important tool to ensure safe operation is provided by the central Safety System (cSS) and central Operational Management (cOPM), [3],[9],[11] ,[12].

The cOPM covers operational management and sequence control (slow control) for different operational phases of the device. The main function of the central device control is to guide and control the global behavior of the W7-X basic machine.

The cSS of W7-X consists of two parts. The safety related PLC with its corresponding periphery, such as sensors and actors, fulfills the requirements of occupational safety and ensures basic investment protection. The cSS handles all requirements for the personnel safety as primary requirement and investment protection (device safety). The safety system of W7-X uses special certified safety hardware. The cSS includes dedicated roughly $40 \mathrm{SIF}$ (safety instrumented functions) for personnel and device safety that automatically activate when required operational conditions for a specific system are not met [11]. As an example, exceedance of NBI beam dump thermal couple temperatures will automatically shut down the heating systems (ECRH, NBI, ICRH) [13]. The safety levels as mentioned in chapter 5 aid in automatically assigning or revoking system allowances for operation.

The reaction time from the signalization of dangerous faults to the initiation of protection measures like W7-X emergency stop or media shut-off is in the range of some 100 milliseconds.

\begin{tabular}{|c|c|c|c|c|c|c|c|c|c|}
\hline \multicolumn{2}{|c|}{ Monday } & \multicolumn{2}{|c|}{ Tuesday } & \multicolumn{2}{|c|}{ Wednesday } & \multicolumn{2}{|c|}{ Thursday } & \multicolumn{2}{|c|}{ Friday } \\
\hline 7:30-13:00 & 12:45-18:15 & 7:30-13:00 & 12:45-18:15 & 7:30-13:00 & 12:45-18:15 & 7:30-13:00 & $12: 45-18: 15$ & 7:30-13:00 & $12: 45-18: 15$ \\
\hline TH open & GDC* & \multicolumn{2}{|c|}{ Plasma OP } & \multicolumn{2}{|c|}{ Plasma OP } & \multicolumn{2}{|c|}{ Plasma OP } & \multicolumn{2}{|c|}{ TH open } \\
\hline
\end{tabular}

Table 3 Coarse overview of typical operational week $\quad{ }^{*}$ GDC: glow discharge cleaning 
Because this is not sufficient to protect components in the plasma vessel in case of overloading by plasma heating, a fast interlock system was implemented [14] and represents the second part of the cSS.

The central fast interlock system (cFIS) as part of the cSS and local fast interlock systems (IFIS) in several heating systems have been installed. Together with a set of safety relevant diagnostics, this system is able to react to dangerous situations within ms. Basically all systems are monitored by the respective ROs through WinCC $®$ "faceplates" on the Clients within the control room. As mentioned in chapter 3 for several systems control takes place in dedicated control rooms.

\section{Structural and thermal monitoring}

For monitoring mechanical and thermal loads of the vessels, magnet-support-structure and in-vessel components a large set of machine instrumentation is available [15]. On top of that, infrared observation is available for the highly loaded in-vessel components [16][17]. This data is being collected and distributed through a dedicated Archive-Database [18]. The DOT has access to this data through dedicated software packages for analyzing and post processing relevant data [19][20][21].

The TLvD also keeps an eye on the segment control program that is the heart of the plasma control system [20]. The programming is done by the SL, but the TLvD should ensure that the programs prepared for a particular session correspond to the machine limitations and scientific goals for that specific day. The TLvD looks primarily at heating system sections of the segment program to ensure that the heat load and total amount of energy deposited into the plasma vessel is staying below agreed limits [22].

As mentioned in the previous chapter, during an operation campaign (incl. commissioning) the vital support systems of W7-X are running 24/7. The DOT is thus continuously required through duty-on-call to be able to react in case of technical issues even outside of operating hours. This duty-on-call is covered by the TLvD and ROs of the active systems from Fig. 7 for the entire campaign (Fig. 3). A high level of training is required to ensure fast and proper reaction to technical issues and thus minimizing operational delays.

\section{Documentation and Procedures}

For preparation, execution and evaluation of operational phases a large set of documentation procedures have been established within the project. For the commissioning phase the commissioning assurance template (CAT) [6] ensures proper planning and execution of the commissioning of single systems and the entire W7-X.

\section{Checklists}

For each day of operation, the TLvD has several checklists at hand to aid him in coordinating daily startup and shutdown of W7-X. These checklists ensure personnel and device safety by maintaining the proper and complete order of actions.

\section{Logbooks}

To comply with the radiation protection regulations a central paper logbook is required. The TLvD documents all radiation protection related activities during operation. An electronic logbook is available which enables the TLvD to document operational activities in free text form as well as system related events [23]. Each main system (heating, vacuum, magnet power supply and periphery) also maintains local logbooks for later reference. To log detailed information on each plasma program the EL and all ROs of diagnostics and peripheral systems have access to the segment program logbook [24].

\section{Magnet configurations}

To ensure that W7-X is operated within its operational limits it is very important that proper planning and release of magnetic configurations is established. Each configuration of currents has to be assessed and released by engineering and the magnets operations team [21],[22],[25]. This also requires a formal release procedure by the physics proponent for each individual session as technical boundaries can always change on a day-to-day basis.

\section{Energy release procedure}

In 2017 and $2018 \mathrm{~W} 7-\mathrm{X}$ has performed the experimental phase (OP $1.2 \mathrm{a} / \mathrm{b})$ with an inertially cooled test divertor unit (TDU) [26]. The divertor operation resulted in a substantial improvement of the plasma parameters compared to the first OP1.1. Heating was increased from $4 \mathrm{MJ}$ in OP1.1 up to $200 \mathrm{MJ}$ in OP1.2b including $5 \mathrm{MW}$ $30 \mathrm{sec}$. plasma pulses. This heating energy increase has been performed in several steps [22], in a dedicated procedure, identifying hotspots of localized energy deposition with thermography cameras and measuring the instantaneous temperature increase on the target plates, baffles and the walls as well as the slow temperature increase of divertor structures. Further, the plasma impurities have been monitored during the increase of the integrated power deposition in the device to detect a possible overloading of the first wall. The increase of integrated power deposition in the plasma was strongly depending on the magnetic configuration, which is also taken into account for this release procedure.

\section{Issues during operation}

In daily operation numerous technical issues can occur that need to be addressed with a certain urgency. To keep track of these issues, the TLvD has to document each issue by an operations stop card (OSC) and involve all relevant parties to get it solved, e.g. TL, EL, Quality Management (QM), the RO Machine-Safety as well as the RO for the systems involved. In case of more substantial technical issues, the responsible mechanical and electrical engineers are also involved or the issue will be transferred to a committee which includes the scientific departments. If special activities (short term maintenance etc.) on running systems are required, this has to be requested to the TLvD through special permits. 


\section{Outlook}

The first operational phases of W7-X have shown that the organization of device operation ensured an efficient operation of W7-X. The experience gained is used to optimize planning, communication, procedures and documentation. For the upcoming OP2 with high heat flux divertor, it is planned to integrate the planning, release and documentation tools into a central online database. This will then be able to link information through the logbooks for easy access and reference reducing redundant information. The TLvD have to be trained even more intensively as in-vessel heat loads will increase substantially during OP2 towards 30 Minute full power plasma operation [27].

\section{Acknowledgments}

The author would like to thank all contributors and the DOT of W7-X. This work has been carried out within the framework of the EUROfusion Consortium and has received funding from the Euratom research and training programme 2014-2018 and 2019-2020 under grant agreement No 633053. The views and opinions expressed herein do not necessarily reflect those of the European Commission.

\section{References}

[1] H.-S. Bosch et al., ,Final integration, commissioning and start of the Wendelstein 7-X stellarator operation", Nucl. Fusion 57, 116015 (2017) (9pp).

[2] H.-S. Bosch et al., „Transition from Construction to Operation Phase of the Wendelstein 7-X Stellarator", IEEE Transactions on Plasma Science 42 (3) 432-438 (2014).

[3] J. Schacht, et al., Task and structure of the Wendelstein 7X control system, Fusion Eng. Des. 81 (2006) 1799-1806.

[4] A Spring et al., "Establishing the Wendelstein 7-X steady state control and data acquisition system during the first operation phase", Fusion Engineering and Design $123 \cdot$ January 2016.

[5] S. Dumke et al., "Next generation web based live data monitoring for W7-X", Nucl. Fusion Engineering and Design, Volume 129, April 2018, Pages 16-23.

[6] H.-S. Bosch et al., "Experience with the commissioning of the superconducting stellarator Wendelstein 7-X", Fusion Engineering and Design, Volumes 96-97, October 2015, Pages 22-27.

[7] T Klinger et al., „Technical challenges and first operation of the Wendelstein 7-X superconducting stellarator", The Technology of Fusion Energy (TOFE 2018), Orlando, FL, USA, 11th November 2018.

[8] H.P. Laqua et al., "Overview on W7-X results in the operation phase OP1.2“, 22nd International Stellarator and Heliotron Workshop, Madison (Wisconsin, USA), 23rd September 2019.

[9] J. Schacht et al., "Realization of the requirements for a safe operation of Wendelstein 7-X", 12th IAEA, Daejeon, Republic of Korea, 13th May 2019.

[10] C.P. Dhard et al., "Refrigerator operation during commissioning and first plasma operations of Wendelstein 7-X”, Fusion Engineering and Design, Volume 123, November 2017, Pages 111-114.
[11] R. Vilbrand et al., "Application of the engineering standard for functional safety to the W7-X central Safety System", Fus. Eng. Design, 123, 632-636 (2017).

[12] J. Schacht, et al., "Task and structure of the Wendelstein 7-X control system", Fusion Eng. Des., 81 (2006), pp. 1799-1806.

[13] P van Eeten et al., "W7-X NBI beam dump thermocouple measurements as safety interlock", Fus. Engin. and Design, Volume 146, Part A, September 2019, Pages 1329-1333.

[14] Vilbrandt et al., "First version oft he W7-X Fast Interlock System“, 12th IAEA, Daejeon, Republic of Korea, 13th May 2019. To be published in Fus.Eng. Design 2019.

[15] J. Fellinger et al., "Preparation for commissioning of structural sensors of Wendelstein 7-X magnet system", Fus. Eng. and Design, Volumes 98-99, October 2015, Pages 1048-1052.

[16] D. Naujoks et al., "Loads on plasma wall components in W7-X and corresponding limits", 9th International workshop on "Stochasticity in Fusion Plasmas (SFP)", Bad Honnef, Germany, 8th April 2019.

[17] M.W. Jakubowski et al., "Infrared Imaging Systems for wall protection in the W7-X stellarator", 18th HTPD, San Diego, USA, 16th April 2018.

[18] C. Hennig et al., "ArchiveDB-Scientific and technical data archive for Wendelstein 7-X", Fusion Engineering and Design, Volume 112, 15 November 2016, Pages 984-990.

[19] A Carls et al., "A structural integrity monitoring tool for Wendelstein 7-X", Conference : SOFT 2016, Prague, Czech Republic, 5th September 2016.

[20] A. Spring et al., "Establishing the Wendelstein 7-X steady state plasma control and data acquisition system during the first operation phase", Fusion Engineering and Design, Volume 123, November 2017, Pages 579-583.

[21] V Bykov et al., "Engineering Challenges of W7-X Mechanical Monitoring during Second Phase of Operation", The Technology of Fusion Energy (TOFE 2018), Orlando, FL, USA, 11th November 2018.

[22] H.-S. Bosch et al., "Operation of W7-X with an inertially cooled divertor - on the way to steady state operation", IEEE Trans. Plasma Science, 2019.

[23] M. Grahl et al., "The new W7-X logbook - A software for effective experiment documentation and collaborative research at Wendelstein 7-X", Fus. Eng. and Design, Volume 146, Part A, September 2019, Pages 1254-1257.

[24] A Spring et al., "A Metadata Framework for Assisting Experiment Planning and Evaluation at W7-X", 28th IEEE Symposium on Fusion Engineering (SOFE 2019), Jacksonville, USA, 2nd June 2019.

[25] K. Risse et al., "The magnet system of Wendelstein 7-X stellarator in operation", Fusion Engineering and Design, Volume 136, Part A, November 2018, Pages 12-16.

[26] T. Sunn Pedersen et al., "First results from divertor operation in Wendelstein 7-X", 2019 Plasma Phys. Control. Fusion 61014035.

[27] OG Grulke et al., "Wendelstein 7-X: Towards high-density, long-pulse operation“, 46th Conference on Plasma Physics (EPS), Milan, Italy, 8th July 2019. 